\title{
10
}

\section{Exploring Analyst-Client Communication: Using Grounded Theory Techniques to Investigate Interaction in Informal Requirements Gathering}

\author{
C. Urquhart \\ Department of Information Systems \\ University of Melbourne \\ Parkville, Victoria, Australia \\ Tel: $\quad+61393449248$ \\ Fax: +61393494596 \\ E-mail: c.urquhart@dis.unimelb.edu.au
}

\begin{abstract}
This paper describes a case study in client-analyst interaction during the requirements gathering phase. The focus of this work is a discussion of interactional tactics used by analysts and clients to facilitate shared understanding and agreement and how this may impact on conceptualization of information systems. The paper also describes in detail methodological issues encountered when analysing conversational data and how these issues were resolved by application of grounded theory techniques allied with other qualitative techniques. Finally, the paper gives some suggestions as to how the findings could assist current practice in systems analysis, particularly with regard to how systems analysts might better structure their interactions.
\end{abstract}




\section{INTRODUCTION}

The requirements definition phase of an information systems project is of necessity a problematic process, founded as it is on a very unreliable technique: human communication. The oft heard cry of the practitioner - "users don't know what they want" - contains at least a grain of truth when analyst-client communication can properly be characterized as cross-cultural communication, where use of unfamiliar language that is domain specific on both the part of the analyst and the client can create a barrier to communication. Most cross-cultural studies take culture to be shared knowledge of how to behave and recipes for understanding experience in specific ways (Barnett and Kincaid 1983). Viewed from this perspective, it can be seen how users and analysts might be perceived to come from different cultures. It has also been stated that miscommunication events between cultures are essentially of the same type as intra cultural encounters, and that the problem is perhaps made salient by those differences (Banks, Ge and Baker 1991).

Previous research on analysts and clients has found many differences between the two groups in the areas of beliefs, attitudes, personalities and motivations (Pettigrew 1974; Gingras and McLean 1982; Green 1985; Kaiser and Bostrom 1982; Benbasat, Dexter and Manther 1980; Ferret and Short 1986).

The issue of communication between client and developer has been identified as a major factor impacting on systems development for two decades, since ineffective communication was found to be negatively correlated with project success (Edstrom 1977). In 1994, the Australian Computer Society devoted a whole issue of its practitioner magazine to the problem of communication with users (Kennedy 1994). In longitudinal studies over ten years of researching computing professional characteristics (Dengate, Cougar and Weber 1990), computing professionals have been characterized as having low social needs, resulting in a need for communication skills training. The authors of that study felt there had been no improvement in the area of communications skills during the lifetime of the study.

Those studies that have explored analyst-client communication by studying analyst-client pairs (Tan 1989; Guinan 1988) have variously identified rapport, client communication skills, analyst performance skills, communication competence and frame flexibility as factors in successful interactions. Tan found that communication satisfaction was determined by perception of rapport rather than goal achievement. Goal achievement was not found to be positively linked to communication satisfaction - for example, both parties may have found the communication successful even though it did not achieve their original goals.

Given that the starting point of all requirements gathering is a verbal interchange between analyst and client, then it is not unreasonable to assert that how communication skills are employed will have a significant bearing on perceptions between client and analyst. Systems requirements verbalized by the client will be encoded into a set of system requirements by the analyst. This in turn becomes the reality of the new 
system. If the initial precepts on which the system is based are false or inaccurate, then there is every possibility of system failure.

The case study described in this paper is an attempt to explore how that communication takes place, and how the analyst and client work toward a shared perception of requirements. Of necessity, the words they use, and how they use them, represent the starting point. Language forms have been described by Candlin (1985) as

the surface realization of those communicative strategies involved in the interactive procedures working amongst those various social, contextual, and epistemological factors...identified as crucial to the process of communicative inference and coherence.

In an analyst-client interaction, a shared perception of requirements is essentially the crux of the matter and arguably the most important outcome. It is also most difficult to observe or measure, given Candlin's point that language is merely the surface realization of communication and that there are a number of "underground" processes to be considered when examining the communicative inference and overall coherence of an interaction. Coherence is said to be the extent to which a discourse "hangs together," in terms of how relevant successive utterances are to those that precede them and to the concerns of the discourse as a whole (McLaughlin 1984). Communicative inference is much more complex, concerned with how people assign meaning to what they hear and how they make sense of information they receive. There are many views of how this might occur: for instance, the field of symbolic interactionism contends that meaning is constantly negotiated between individuals in the form of symbols (Wood 1982). In cognitive theory, Dervin (1983) puts forward a sensemaking approach which assumes information to exist to a significant degree internally and assumes users of information to be making sense of it literally on a moment by moment basis. Bateson (1972) evolved a theory of framing behaviors based on levels of abstraction. Watzlawick, Weakland and Fisch (1974) extended this concept through to the notion of a reframe - essentially the meaning attributed to a situation is altered while the concrete facts remain the same. Guinan, in her study of analyst-client interaction, defined the concept of "perceptual correspondence" - where interactants assume they are seeing things the same way - and posited that this occurred through problem framing and reframing.

The case study described in the following pages was designed to explore analyst-client interaction from a processual perspective. Previous studies (Guinan 1988; Tan 1989) attempted to measure certain analyst behaviors and link them to outcomes. Neither study considered contextual factors or the process by which an analyst and client might come to an agreement. Furthermore, as both studies were quantitative in nature, there was little opportunity to examine analyst-client dialogue at the micro level or to consider how perceptual correspondence might develop over the lifetime of the interaction.

The case study has as its general focus the question "How do analysts and clients reach a shared understanding of system requirements?" More specifically: 
- what conversational tactics do analysts and clients use to build up a joint picture of the system under discussion? and

- what conceptual schemas do analysts and clients employ with regard to systems?

By looking at the participants' interpretations of the interaction and other data sources, it should also be possible to ascertain which of these tactics and schemas are helpful to analysts and their clients.

\section{METHODOLOGY}

This section of the paper describes how the case study was designed, the motivation for that design, how grounded theory techniques were chosen as the main qualitative tool of analysis, and how they were applied to this particular case study. When encountering qualitative analysis for the first time, one is struck by both the number of methods and the difficulty of analyzing and presenting large amounts of data. The objective of interpreting the data in such a way that it allows people who have not directly observed the phenomena to obtain a deeper understanding of it, without applying a pre-existing theory to the data (Feldman 1995) is a formidable one. This objective requires a thorough examination of the most appropriate research method and careful consideration of how best to present the findings.

\subsection{Case Study Design}

The case study described in the paper is one of a series of six case studies employing multiple data sources. These data sources include a videotaped interaction between the client and the analyst, a review of that interaction (also videotaped), and audio recordings of individual interviews with both the client and analyst (before and after the interaction). Two questionnaires were also used - one a rapport measure, the other attempting to measure conversational sensitivity of the individuals concerned. According to Yin (1984), case studies can involve single or multiple cases and numerous levels of analysis. The case study design incorporates triangulation and has as its main focus the interaction which takes place between analyst and client. The interaction in each case discusses a real life case of systems requirements, and takes place at either the analyst's workplace or the client's workplace. This paper focuses on the qualitative analysis of the videotaped interaction and its review.

The multiple data sources have been chosen to give as many insights into the interaction as is feasible and to assist in theory generation. The review of the videotaped interaction by the participants is an important element of the case study as it enables a multiple interpretation of the realities of the interaction; similarly, individual interviews enable both participants to articulate what realities they are bringing to the interaction. The post interaction interview also gives insights into outcomes as the 
participants perceive them. Videotaping enables consideration of nonverbal factors and paralinguistic features. The rapport measure is a standard instrument which enables yet another view of the interaction. The measure of conversational sensitivity (Daly, Vangelisti and Daughton 1987) gives an indication of whether the participants are predisposed to pick up on hidden meanings in conversation and was itself developed using grounded theory techniques.

\subsection{Conducting the Case Study}

All six case studies were carried out in the public sector in Tasmania. IS managers were approached and asked if systems analysts in their employ were carrying out development work and would be willing to participate in the research project. The criteria for inclusion in the project were that the development work had to be at an initial stage (generally the first or second meeting between analyst and client about the development work in question) and that the interaction to be videotaped should either be about the development of a new system or a substantial amendment of an existing system. Several potential cases were rejected on the grounds that all the initial requirements had already been gathered.

Participants were asked to furnish a one page description before the planned discussion. The purpose of this was to both ensure that the interaction fell within the definition of informal requirements gathering and to give insight into initial individual perceptions. The objectives of the study - to investigate how analysts and clients reach agreement - were clearly spelled out as were assurances of confidentiality. Videotaping of interactions seemed to present no difficulty from the participants point of view : in practice, those who were initially nervous soon forgot the camera's presence. Videotaping seems to have little impact on anxiety and responsiveness, as evidenced by nonverbal behaviors generally held to be beyond interactants' control (Weimann 1981).

Motivations for joining the study varied. Some analysts were encouraged to do so by their managers, and others felt they would benefit by examining their communication style. Clients were attracted by the opportunity to review the video tape and discuss the process from their perspective.

\subsection{Deciding on a Method of Analysis}

There are many ways of analyzing spoken texts and a number of approaches were considered before settling on the use of grounded theory technique. These approaches come from diverse fields and all offered the possibility of different insights on the data. These were evaluated from two perspectives: whether the approach drew on all features of the case study and whether the philosophy of the approach imposed preexisting theories of interaction. There may be special features of analyst-client conversation, as a phenomena in a professional setting, that may not be served by adopt- 
ing a purely social interactional approach. Requirements gathering represents a bounded situation which has some standard features and the overt objective is not to socially interact but to converse in order to solve a given problem.

Previous studies (Guinan 1988; Tan 1989) employed content analysis according to a strict predetermined coding scheme. Conversational analysis is a much used approach and focuses on discovering structures and orderliness in interaction (Psathas 1995). Goffman $(1967,1981)$ did much pioneering work in this area and introduced many new concepts for describing interaction. However, use of conversational analysis, while very informative about social structures and giving a processual perspective, was not appropriate for two reasons. First, its orientation toward social relations gives limited insight into how a client and analyst might reach agreement in a professional sphere. Second, the adjacency pair concept means that analysis is confined to pairs of sentences rather than examining a temporal whole.

Discourse analysis sets a broader agenda (Coulthard 1985) and incorporates diverse elements such as consideration of tonality and speech acts, but much of the analysis occurs at a micro level rather than considering how an interaction might evolve. In both discourse and conversational analysis, there are also elements of orderliness imposed on the data which can amount to the application of a preexisting theory. However, McLaughlin's work on topics and conversational coherence gives some guidance as to how people structure conversations and this may be important when considering how people might manage an interaction in requirements gathering.

Ethnomethodology, with its emphasis on social meaning and tacit knowledge, might be considered a suitable approach, but again its focus on social-cultural rules might not reveal all there is to know about the process by which analysts and their clients reach shared understanding.

The field of semiotics, which studies systems of signs and has been claimed to treat all cultural processes as processes of communication (Eco 1976), would be a way of exploring client-analyst communication by examining denotive and connative meanings of terms used in system requirements. Using a semiotic approach, however, would not give as many insights as to the processes which analyst and client might employ. Using a deconstructionist approach could also be an option, especially with its aim of seeing words in context and examination of changing contexts on meaning (Manning 1992). However, as in the case of using semiotics, using this approach might restrict consideration only to meaning rather than the process by which that meaning is reached.

As has been pointed out by Candlin when reviewing the field of discourse analysis, structural and processual approaches to analysing texts, while very different, cannot be easily abstracted from each other and this dilemma is not easily resolved.

\subsection{Reasons for Using Grounded Theory Techniques}

Grounded theory method (Glaser and Strauss 1967; Glaser 1978, 1992; Strauss 1987; Strauss and Corbin 1990) is a "qualititative research method that uses a systematic 
set of procedures to develop an inductively derived theory about a phenomenon" (Strauss and Corbin 1990, p. 24). Because it does offer well signposted procedures, it has some attraction for a researcher using qualitative techniques for the first time. More importantly, it is a general style of doing analysis that does not depend on particular disciplinary perspectives (Strauss 1987) and, therefore, would seem to lend itself to information systems research which can be described as a hybrid discipline. The goal of grounded theory in seeking a theory that is compatible with the evidence, that is both precise and rigorous, and capable of replication (Neuman 1994) is also an attractive one. It also has the benefit of producing theory intimately tied with the evidence, so that the resultant theory is likely to be consistent with empirical observations (Orlikowski 1993; Eisenhardt 1989).

Grounded theory method also requires that the researcher demonstrates theoretical sensitivity (Glaser and Strauss 1967; Glaser 1978) by being well grounded in technical literature as well as from personal and professional experience and in collection and analyses of the data (Strauss and Corbin 1990). At the same time, the inductive nature of grounded theory techniques encourages researchers to steer their thinking out of the confines of technical literature and avoid standard ways of thinking about the data (Strauss and Corbin 1990). The interplay between emergent theory and technical literature comes to the fore when extending generalisations from the study. This is achieved by either integrating supplementary or conflicting analyses into the theory by including them as categories or conditions, or criticising them in terms of what has emerged (Strauss 1987).

As use of grounded theory analysis is founded on the premise that the generation of that theory at various levels is indispensible for a deep understanding of social phenomena (Glaser and Strauss 1967; Glaser 1978), it seems particularly suitable for a case study aimed at exploring how systems analysts and their clients reach agreement. It is also useful for understanding contextual and processual elements (Orlokowski 1993) that constitute the main focus of this case study.

\subsection{Applying Grounded Theory Techniques to the Case Study}

First, the transcript of the interaction was subjected to open coding. This is essentially a line by line examination of the data to generate concepts or codes. The exercise is extremely time consuming but yields many rich concepts for the next phase. Open coding quickly forces the researcher to break apart and fracture the data analytically, leading to grounded conceptualization (Strauss 1987). Axial coding, examining codes in terms of the coding paradigm of conditions, interaction among the actors, strategies and tactics, and consequences (Strauss 1987), was then carried out. The use of this paradigm enables the researcher to link subcategories to a category in a set of relationships and also enables further dimensionalisation of categories (Strauss and Corbin 1990).

It should be noted at this point that Glaser (1992) has criticised the paradigm in particular and the publishing of strict procedures in general (Strauss 1987, Strauss and 
Corbin 1990). Glaser regards the paradigm as "forced conceptualization" of data and says categories should be allowed to emerge naturally. (Further discussion of this area of important disagreement between the co-originators of grounded theory will be provided in later sections.) Strauss does point out that the procedures outlined should be thought of as rules of thumb, rather than hard or fixed rules, and advises researchers to study these rules of thumb, use them, and modify them in accordance with the requirements of the research.

\subsection{Applying the Paradigm and the Adaptation of Grounded Theory techniques}

During axial coding, the application of the paradigm to the open codes was used selectively. It was viewed not only as an aid to understanding the relationships between open codes and emergent categories, but also as a means of drawing some preliminary distinctions in the data. When examining the open codes generated from the transcript, using the paradigm of conditions, interaction among the actors, strategies and tactics, and consequences, it was found that the open codes tended to fall into one of two areas: those associated with interaction aspects (interaction among the actors, strategies and tactics) or those associated with the conceptualization of the information system (conditions and consequences). This drew a natural distinction in the data and also allowed the research questions to be addressed in a straightforward manner. Interaction and conceptualization can also be thought of as emergent core categories. Obviously there was an element of choice in applying the paradigm in this way. For instance, some conditions and consequences could be found among interactional aspects, but it was found that the vast majority of conditions and consequences did apply to the conceptualization of the information system (the topic under discussion), rather than how the discussion was managed vis-à-vis interaction. That the data naturally fitted the paradigm in this manner, rather than being forced, supports its selective application in this particular case.

The methodological question of whether to start with predetermined categories or to start with line by line coding is one that confronts all qualititative analysts. Dey (1993) recommends a middle order approach, where some broad distinctions are drawn initially, based on fairly common sense categories. Analysis can then proceed in either direction, toward subcategorization or linking and integrating the middle order categories. In this case study, rich concepts were yielded using line by line coding, and the subsequent application of the paradigm in a selective fashion enabled a focus on the research questions.

The application of the paradigm in this manner gave an additional benefit, as the distinctions made go some way to abstracting the processual/structural dichotomy evident in discourse analysis. Attention can be given to the social processes by which analyst and client reach agreement and structural analysis of the text can give insights as to how an analyst and client might jointly conceptualize an information system. 
The relationship between the emergent core categories, and subcategories, can be regarded as the interplay between social processes and how the dialogue itself is structured as a consequence. Another way of viewing this distinction is to say that what is of interest in this study is how the participants manage the interaction, and how the management of that interaction impacts on the subsequent conceptualization of the information system.

Table 1 illustrates how the paradigm was selectively applied, with some sample codes that were generated during the open coding phase.

Table 1 Application of Paradigm to Open Codes.

\begin{tabular}{|c|c|c|}
\hline $\begin{array}{c}\text { Emergent Core } \\
\text { Category }\end{array}$ & Paradigm Items & $\begin{array}{c}\text { Samples of Initial } \\
\text { Open Codes }\end{array}$ \\
\hline Interaction & $\begin{array}{l}\text { Interaction among the actors } \\
\text { Strategies and tactics }\end{array}$ & $\begin{array}{l}\text { acting out, imagining, vivid de- } \\
\text { scription, posited action, prop, } \\
\text { reframe }\end{array}$ \\
\hline Conceptualization & $\begin{array}{l}\text { Conditions } \\
\text { Consequences }\end{array}$ & $\begin{array}{l}\text { information source, information } \\
\text { type, document ref, computer sys- } \\
\text { tem ref, clerical system ref, infor- } \\
\text { mation link, process identification, } \\
\text { condition, client action }\end{array}$ \\
\hline
\end{tabular}

While using the paradigm to consider relationships it became clear that an alternative way of examining relationships between sub categories had to be sought. As the paradigm had also been used to draw distinctions in the data, it became more complex to apply when considering relationships between codes. For instance, it is difficult to think of conditions as both pertaining to the information system under discussion and also pertaining to interactive social processes; yet clearly causal and other relationships exist between the two.

Spradley's (1979) domain analysis was used to assist formulation of relationships between codes and categories. Spradley defines a domain as an organizing idea or concept, akin to a category in grounded theory methodology. These domains can contain "folk" terms, used by the members of the social setting, analytic terms generated by the researcher and relevant theories, and mixed domains containing folk terms to which the researcher adds other terms. In grounded theory methodology, these translate into "in-vivo" codes used by the participants, the concepts generated by the researcher during open coding, and theoretical sensitivity demonstrated by using terms from the technical literature.

In addition, Spradley provides semantic relationships that can exist between domains. The benefit of using these semantic relationships was that they allowed a finer grained analysis of relationships between codes. They enabled an extension of causal conditions, intervening conditions and consequences given in the later version of the paradigm provided by Strauss and Corbin. These nine semantic relationships 
vary from strong causal relations to those that specify characteristics. The nine relationships are a kind of, is a part ofla place in, is a way to, is used for, is a reason for, is a stage of, is a result/cause of, is a place for, is a characteristic of. Other than the references to place which presumably are important for studying social settings, these relationships seem to offer enough variation to cover most kinds of connections between categories, but are comprehensive enough to offer ease of use.

An alternative route would have been to use one or two of the theoretical coding families advanced by Glaser (1978). There are eighteen families proposed in all, some of which would be applicable. Spradley's semantic relationships would seem to cover at least some of the informing ideas of these families. It is proposed to use some of these theoretical codes when extending the theory to other case studies, if further application of Spradley's relationships prove not to cover all possible eventualities.

Another view of the coding process is presented in Figure 1. Here the emergent core category of conceptualization contains three subcategories, actions, processes and information, found to be key to conceptualizing information systems in the case study. Two of these subcategories, actions and information, have subcodes represented in the boxes. Actions and information are seen as having a relationship with processes. No subcodes were generated for processes, as processes were seen as being at a higher level of abstraction than either actions or information. The emergent core category of interaction is here entitled interaction tactics and some subcodes for this category are provided. The relationships A, B, C, and D use Spradley's relationships and are seen as initial theories as to the nature of the relationships between the core categories and subcategories. Some of the subcodes represented in the boxes have relationships between themselves as well as with the subcategories. The advantage of using Spradley's domain analysis is clear: it prevents consideration of codes as purely hierarchical and so allows the consideration of all types of relationships and the generation of a rich theory. Instances of codes, categories and subcategories are illustrated by examples of dialogue found in the findings section of the paper.

\subsection{Using Analytic Memos and Integrative Diagrams}

During the axial coding phase, integrative diagrams and analytic memos were used to consider relationships between codes and to develop theory. The use of analytic memos and integrative diagrams are suggested by Glaser and Strauss, Glaser (1978), Strauss, and Strauss and Corbin and are viewed as critical for theory development. They should be utilized throughout the lifetime of the project and Strauss and Corbin go so far as to suggest that sparse use of these tools will result in a theory which lacks density. Use of analytic memos provide an opportunity for the qualitative researcher to think aloud, explore new categories, integrate borrowed concepts, and establish the grounding of concepts. Analytic memos are a generic tool in qualitative research (Neuman 1994), and are not confined to use in grounded theory method. In this case study, they were found to be most helpful when considering how codes might be 


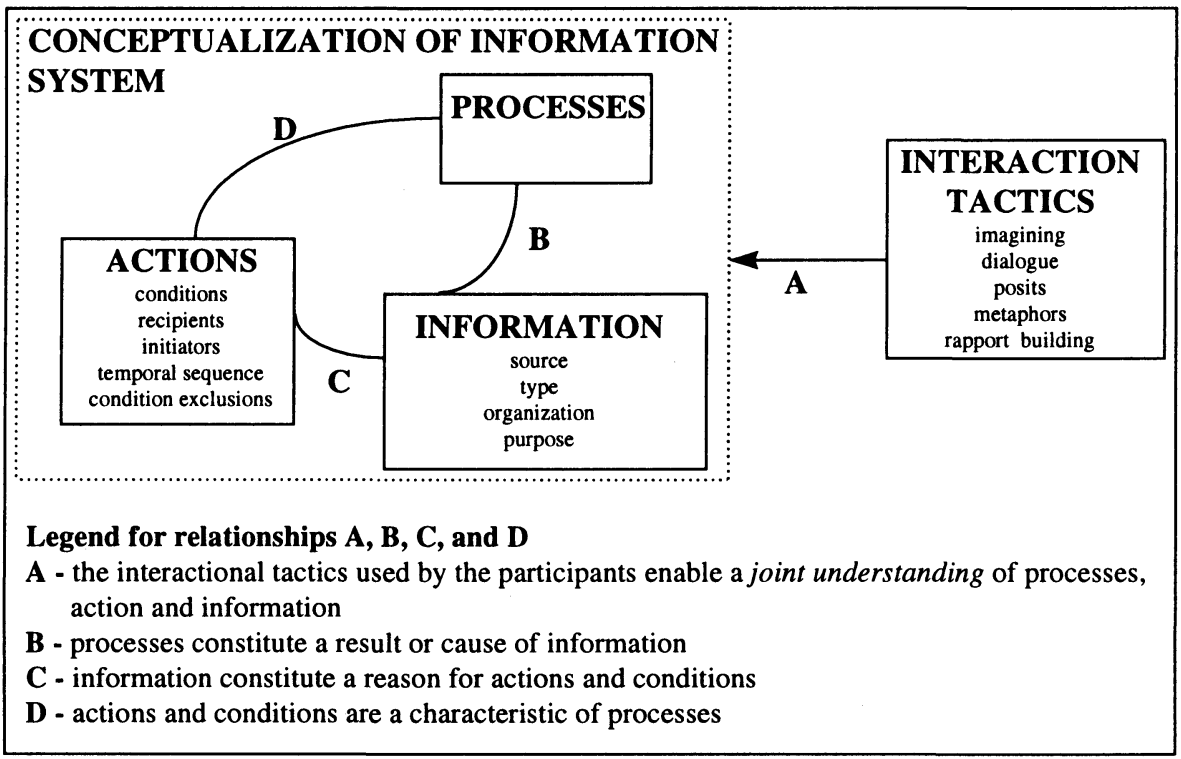

Figure 1 A View of Initial Core Categories and Subcategories Generated by Axial Coding.

grouped and what relationships existed between them. In addition, it was found useful to illustrate emergent concepts by relating back to instances in the data to ensure that the emerging theory was truly grounded. Appendix 1 gives an excerpt of an early analytic memo on the interaction of clerical and computer systems in the case study.

Integrative diagrams were used extensively during the axial coding process to assist understanding of relationships between codes and grouping of codes, and to bring together various analytic clusters (Strauss 1987). Spradley's relationships in domains were assigned between various clusters. An example of an integrative diagram pertaining to interactional aspects is reproduced in Appendix 2. Note that this diagram makes a distinction between those interactional tactics used when gathering information and those used to facilitate understanding. This distinction is described in a further analytic memo on tactics; briefly, participants have a battery of tactics that they use depending on the difficulty of the subject matter.

\section{FINDINGS}

Presentation of the findings in this case study presented some challenges as how best to give readers a feel for the case study data, given the limited space afforded by an 
academic paper. When presenting qualitatively analyzed data, there is the problem of whether to weave interpretation and description together or allow them to stand as separate entities (Wolcott 1990). Wolcott advises the presentation of a descriptive account without heavy handed or intrusive analysis. The nature of qualitative research lends itself to multiple interpretations of the data. There is also the objective of giving a feel for how the participants construct meanings and create interpretations (Neuman 1994) to take into account. Communications researchers in general seem to take a highly selective approach to the presentation of their data, and this has been criticised on the basis of providing an insufficient database on which to build rules (McLaughlin 1984) or theory. When presenting grounded theory studies, researchers are advised to opt for a narrative chronology where categories and subcategories are related to the story line (Strauss 1987).

The findings, therefore, have been presented as chronological episodes from the interaction, together with illustrations of analytic concepts generated by applying grounded theory techniques to the dialogue being described. These analytic concepts are represented in italics. It also attempts to incorporate idiographic or thick description (Wolcott 1990. Neuman 1994) by not only illustrating analytic concepts but also incorporating a narrative or story line.

Episodes in this context can be regarded as akin to subtopics in the transcript. In practice, it is relatively straightforward to identify topic shifts. Planap and Tracy (1980) demonstrated that this can be done with a high degree of reliability by most people. In their study, twenty subjects were asked to read transcripts and view videotapes, and twenty subjects to read transcripts. Reliabilities for topic shift were quite high: .926 in the first case, .919 for the second. The videotape did not assist much in identifying topic shift, verbal cues seemed sufficient.

The episodal approach used here also allows readers to develop an understanding for how the interaction moves through distinct phases in terms of building rapport and seeking solutions. It also allows the actors to speak in their own voices and allows for multiple interpretations (both important goals for interpretative research). The concepts that are italicised generally refer to open codes or subcategories rather than full categories. Where appropriate, commentary has been added as to how these relate to emergent core categories.

Another reason for opting for this mode of presentation is that contextual and processual factors are a focus of the case study. Episodal presentation urges the reader to consider the interaction in the context of its larger temporal whole.

\subsection{Interactional Tactics and the Conceptualization of an Information System}

Throughout the episodes presented below, two clear themes relating to the emergent core categories are evident. 
First, the interactional tactics employed by the analyst and client to facilitate the discussion at hand are found throughout the interaction. Episodes 1 and 2 illustrate how the analyst and client agree on the objectives of the discussion and how to discuss those objectives. Episode 4 demonstrates how the analyst uses posits for information gathering, and Episode 5 illustrates a battery of tactics utilized to facilitate understanding of the problem. An integrative diagram giving the relationships between some of these categories is found in Appendix 2.

Second, how the conceptualization of the information system proceeds is also demonstrated by Episodes 1 through 6 . In Episode 3, we see the identification of various information types by the analyst. In Episode 5, the consideration of conditions, and actions associated with various processes or functions is evident.

All open codes, subcodes and categories in the findings are represented in italics to assist the reader.

An additional advantage of presenting the case study in episodes is that it becomes clear that the conceptualization is intimately intertwined with interactional tactics. Without appropriate tactics, it is difficult to gain appropriate information for conceptualization. Without appropriate conceptual tools, it is difficult to make sense of the information gained.

Episode 1: "Basically we're looking at..."

The analyst commences his interview of the client by saying

What I've done...I've drawn up, a little, sort of a couple, of points from

when we talked last... when you gave me an overview of the system.

In addition to providing a starting point for the conversation, the analyst seems to be trying to gain trust by using the tactic of deprecation - what he has drawn up is only "a little," "sort of," "a couple" of points and therefore is not threatening. The use of personal references is also interesting - "we" spoke last and "you" gave the overview of the system, the inference being one of joint ownership.

The analyst then proceeds to outline what he perceives as the function and purpose of the system.

Basically what I've sort of got down here is the database is about keeping statistics of approved and nonapproved students, for a Student Grants Scheme.

The client confirms this; so far she has said very little.

The analyst goes on to outline a possible objective for the conversation. It is interesting to note that, perhaps not unreasonably, his primary focus is on the computer database rather than the clerical scheme it supports, and his signalling of the intention that the "improving" be a joint ownership exercise by the use of "we."

Basically we are looking at...how the database works and possibly some of the points we are thinking about improving...you know, recording of information.

At this point the client interjects

You've got by school have you? 
She seems to be checking that this issue is within the scope of objectives being outlined for the amendment. The analyst confirms this, and also mentions a number of other functions or processes and "general things we are thinking about as we are going along." It can be seen that this episode sets the template for what is to be discussed, but that the interactional tactics used to manage the discussion are still evolving.

\section{Episode 2: "Maybe if you can give me a bit of a run down"}

Here the analyst and the client come to an agreement as to how to discuss the problem, having agreed on what the general objective is. This episode represents an interesting negotiation, as it illustrates how two people resolve the issue of possibly conflicting ideas on how to conduct the process. The analyst starts by saying

But to get to that sort of point what I've got to...we need to try and work out, or I need to work out what the actual database does and how it functions at the moment?

There is a pronoun shift from "we" to "I" as the analyst makes clear what his personal objective for the interaction is but also requests joint ownership. Again it is interesting to note in the light of later interaction that the stated area of analyst interest is the database. Most of the subsequent interaction, in fact, hinges on the relationship between the database and the clerical procedures it supports, as later episodes will show. But to return to the present episode, the client agrees to his statement and the analyst then goes on to make clear the intended outcome of his objective:

So we'll be able to look at umm what changes we can make to improve things?

The concept of "improvement" has now been mentioned by the analyst twice in the space of a minute's conversation, and the frequent use of "we" indicates his intention that this be a joint ownership exercise. He then goes on to suggest a process by which things can get started:

So maybe, maybe to start that out, start that off, maybe if you can give me

a bit of a...rundown just to

The client's reaction is rather surprising, she interrupts with

Mmm, I actually just printed a copy of the range for you...for you to have

a look at.

The client may be simply offering information, or suggesting a different process. It may be the latter, given the remark immediately following:

Umm would you like me to go through the procedures we have at the moment step by step or?

The analyst responds with

Yeah that might be, well just as an overview, well just as I said before we've got it's for approved reports statistics for approved or nonapproved applicants.

There are several possible interpretations of this remark - the analyst seems to be reparcelling the clients suggestion to be more in line with his previous suggestion for 
conducting the discussion - "well just as an overview." The restatement of systems functions may be an indication of what he perceives the baseline of the conversation.

The client then responds by giving a reason for those system functions:

$\mathrm{Mmm}$. The reason we need that is because we pay the schools.

The analyst asks if the database helps with assessment of students; the client says it does not and states her desire for a process in this area.

That would be good, if we could get a process...but it's quite involved. It is not clear at this stage whether the client is conceptualizing the notion of a process as a computerized process or a clerical one. By looking at the overall context of the conversation, one can probably assume the former but at this stage it is not clear.

What is evident is that by the end of this episode, both analyst and client have put forward their objectives, and they have (almost) agreed on how to proceed.

\section{Episode 3: "If you could just go through the information"}

In this episode, the analyst and client start to discuss information utilized and generated by the computer system. The analyst makes a request for information by saying

All right, if you could just go through the information you get from schools...and the sort of information you put into the database, so then you've got a list of files that you keep...umm paper records.

Later he adds

I just need to get an idea of what's, what you get from schools and what you actually put into the database.

So here the analyst is delineating between the various information types, held in the database or on paper, and its various forms (files, records) and source (from schools).

The client imposes a temporal order on things by starting from the beginning consistent with her offer to go through step by step. She says:

Each applicant has an application form which is submitted directly to the school, they can't come directly through us because the schools have a recording mechanism too.

The analyst takes the opportunity to establish the ownership of the function or process of assessment by asking

Is it the schools that basically do the assessment?

She replies and gives an insight to the actions that the school carries out.

No. We do the assessment. They gather the information....and collect the application forms.

\section{Episode 4: "You too"}

This episode is notable as it is where rapport building is evident between analyst and client. They are after all only three and half minutes into the conversation. The client is explaining the conditions and information types associated with an action. She explains: 
Umm because they (the parents) need both to apply, the application form and the verification of income...and that can be by umm a tax assessment notice.

She then drops into an aside, and says laughingly:

That's if they've done their tax return - not like me!

The analyst replies:

She says:

Right. I haven't done mine yet.

No, I haven't done mine yet,no. You too... and then drops seamlessly back into the previous topic:

or by a statement of pension or benefit

After rapport building, the interaction seems to flow more easily, as evidenced by what follows immediately afterward. The analyst says:

Right. So what, what sort of information do they send back to you, so you

guys in Student Assistance can assess them?

The language "you guys" denotes an informality that was not present before. The following exchange illustrates a speeding up of the transfer of information from client to analyst, as they repeatedly confirm or agree to what the other has said. It is also interesting to note that in the first statement the analyst makes, there is an effort made to express the function of the system in the client's language:

Analyst: Right, do the assessment, decide whether they are eligible for the scheme.

Client: That's right, so that when the school receives the applications summarize each applicant on a form we have devised...so that is their record of the number of applications they've received

Analyst: Right.

Client: $\quad$...and who the students are.

Analyst: So, so they then send that summary of information do they?

Client: Yes with the application forms.

The analyst starts using an interactional tactic at this point, which is readily identifiable all through the interaction - he makes posits or suppositions about the system based on the information.

\section{Episode 5: "So what happens when?"}

This episode occurs approximately twenty minutes later in the interaction. By this time, the client and analyst have established a rapport with each other and are working jointly to establish the current role of the database supporting the Student Assistance Scheme and associated clerical processes.

This episode gives a number of examples of the analyst determining which actions are associated with which conditions and information when discussing the database and associated procedures. This episode also demonstrates instances of reframing, where either the client or analyst reframe the existing facts as stated to draw new conclusions about what is being discussed, and in doing so progress the interaction 
(Watzlawick, Weakland and Fisch 1974). This episode has been chosen to illustrate various tactics, such as imagining and narrative, that the analyst and client use to assist each other in understanding. It also amply illustrates the complexities of procedure that can exist when a computer system interfaces with a clerical system.

The analyst starts off by saying:

So what happens when you actually receive back something, like a review, umm application or some more information?

The client replies:

Its then reassessed. And then we have to...

The analyst interrupts with a posited action.

So you have to go to the paper files?

The client confirms that this is the case, and goes on to explain the actions that are carried out and some associated conditions:

We actually put all reviews in a separate file, but we still yeah have to go

back to the paper files, and when its being reviewed...to change the detail.

You know, that its now been approved.

The analyst pursues this last point and makes a consequential query about the actions:

If they were approved...what would happen to them then?

The client replies:

We'd have to notify them that it's been approved, and the school.

The analyst reframes the facts in the following manner:

So, through a, through a reply. And if they are still not approved, I guess

you'd still have to send them back a reply.

The reframe enables the analyst to put forward another posited action, which proves to be accurate. The analyst is also trying to pin down a temporal sequence for the action and isolate the condition for the reply. This piece of dialogue is also interesting as it is evident that the analyst is thinking aloud, and quickly enough to formulate a subsequent query on the basis of the reframe.

The analyst and client continue to follow through the chain of actions associated with a review:

Analyst: So once you get a review back, you're going to have to send them a letter regardless of what the outcome of that review is.

Client: Well we usually we notify the school.

Analyst: Oh, right.

Client: Because, its, its...apart from code ones, they're usually not approved, until we receive information, so we...the main thing is to notify the school, if its subsequently been approved.

Various action outcomes, action justifications and action initiators/recipients are identified, and generally the action is associated with a condition - in this example a review having taken place. A condition exclusion is identified "apart from code ones."

A few sentences later, something happens as the client continues to explain what occurs during the review process: 
Analyst: Does the school go back and...

Client: Well, they would then say, yeah, they would then say, oh yes you've been approved, the department has...because they...as far as the client is concerned, they are not approved.

Apart from the way the client anticipates the analyst's query, her statement is interesting as it illustrates how she is literally imagining what takes place, to the extent of assigning dialogue to the school. She uses the same tactic a few sentences later:

It's sort of back to square one, yeah, they, the client will quite often, say, come into the school and say, oh, I sent in more information to the Department can you tell me if I've been approved yet?

The analyst picks up on the same tactic, albeit in a more informal vein:

I imagine the student coming in and giving the headmaster a big serve or something - why haven't I been approved!

As the analyst actually uses the word imagine, imagining, therefore, indicates an "in-vivo code" (Strauss 1987) where the term is taken from or derived directly from the language used by the actors themselves. In vivo codes have analytic usefulness as they are often used precisely by the participants, and they often have very vivid imagery.

\section{Episode 6: "We need just to have a look"}

This episode is the final episode of an interaction that has lasted for approximately thirty five minutes; the participants have been asked to wind up. The analyst says:

Yeah, what we probably need to do now is really have a look at the database...so I can get a look at how its actually working, because it's a bit.... Now I've got a fairly good understanding of the processes you want to have...seeing the information that's on there in real life I guess.

These statements illustrate a number of interesting points: the analyst's use of "we" to indicate joint ownership of future action associated with improvement, an objective advanced early on in Episode 1. There is explicit acknowledgment of the clients requirement for computerisation of various processes. The references to "really," "actually," and "real life" seem to indicate a need to confirm what information has been gathered here, or maybe is an implicit reference to all the "imagining" that has taken place.

The analyst goes on to outline in concrete detail what should take place next time they meet:

Maybe just having a look from the start, maybe just walk through what would happen if you got a bunch of applications and a batch summary sheet. What you'd put in, what would happen if someone is approved, obviously you would tick them on the sheet and their number...but what happens if someone is not approved? The letters you'd produce and that sort of thing.

The analyst is clearly still very engaged with what actions, conditions and information are associated with various processes. 
The client responds with something of a reframe and is evidently trying to make sure that the analyst takes into account the need for solutions. She responds with

Yes, that's what it needs...refining... so that if we do have a client ringing up and saying have I been approved, we can, you know, find it, or the number if a school rings up and says has this person been approved. We can look it up, some sort of reference to the name.

The analyst does not immediately appear to pick up this point, and instead mentions a technical dimension of the problem:

[Because] you've got alot of, twenty seven thousand applicants, so it's alot of information going through there.

Another interpretation of this remark is that the analyst is indicating that he understands it to be a large problem for the client in terms of complexity of information processing.

Subsequent dialogue shows that the analyst both appreciates the problem and is prepared to proffer a solution:

Analyst: And maybe for all the ones that aren't approved, we will have to look at the numbers, maybe looking at the current year's database.

Client: Yeah.

Analyst: I guess we can get it from the statistics, the codes two and four, umm aren't kept in there, I mean the nonapproved codes one.

Client: Yes, and twos and fours, that's the problem area actually.

Analyst: Which means, they, which makes it harder if someone phones up.

Client: That's right.

Analyst: And that's the reason you have to go to the paper file.

Client: We've got to go to the file and say you weren't approved because of so and so.

After demonstrating that he understands the consequences of the problem to the client, he offers a way forward and a possible solution:

Analyst: So probably have a look at the total numbers of those, and see if it is feasible, possibly, to keep some sort of indication, maybe just the reference number of the approval code?

Client: Yeah.

Analyst: ...or the status or something like that?

Client: Sounds exactly what we need.

And so the interaction ends, with both parties in concordance as to the nature of the problem. Over the course of the interaction, they have clearly adopted a joint problem solving approach and have enjoyed working through the problem together. One only has to contrast Episode 1 with Episode 6 to appreciate both the depth of understanding of the problem that has developed between participants and also how informality has increased and assisted with the exchange of information and solutions. 


\subsection{Reviewing the Videotape}

The analyst, client and researcher review the videotape of the interaction. The researcher stops the tape at approximately five minute intervals and asks each participant in turn to tell her what they think is happening in that particular frame. Most of their comments focussed on interactional tactics and how conceptualization proceeded as opposed to specific comments about individual statements they made. For example, the analyst comments about Episode 5:

I think what would have been really useful, looking at that, was maybe if we had used the whiteboard or something...I think my notetaking was a bit suspect. It would have been a lot better if I'd have to really try and say what was happening on a piece of paper in nice clear symbols to tell what was going on. Umm I think my concentration was starting to wane a bit there and I was starting to lose the plot, trying to follow that.

The client added:

Yeah we really needed a flow chart, you know, from this to this.

The analyst replied:

That's something I really should have tried, to do something like that there.

Later he says:

And it probably would have been worthwhile just to take a few minutes out and write what's been happening.

About Episode 6, the client makes an interesting comment about the difficulty of describing detailed procedures and her expectation of his understanding.

I didn't explain alot of it very well...like the codes two to four are actually not approved until they...we get the forms back from the parents and I didn't even explain that. Assumed that they would, you notify the schools, they notify they are not approved at the...yeah. It's sort of an internal process you wouldn't be expected to understand.

The analyst comments on the difficulty of processing the information from his perspective:

Just looking at my notes it isn't really clear the information we've actually come up with and we are into such a really, fairly complex area, and I'm trying to rely on the information I have already got and trying to remember what we've already, what I should already know, what we've already found out...and applying it to our situation.

These comments about the difficulty of the process notwithstanding, in subsequent individual interviews both participants rated the interaction as having gone "very well." 


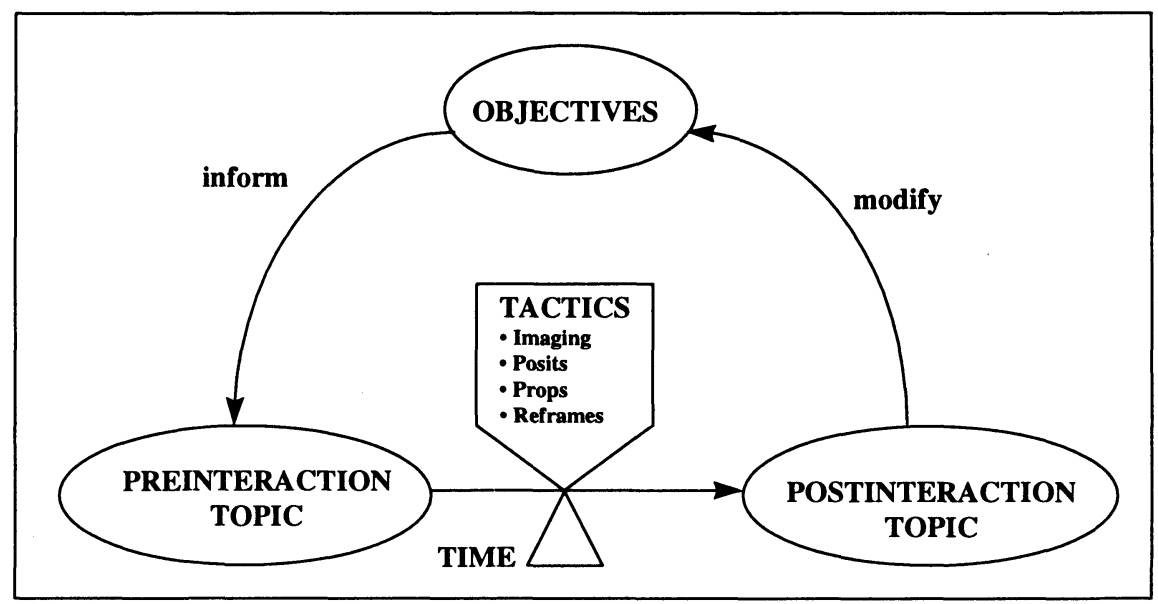

Figure 2 The Role of Tactics in the Interaction.

\subsection{The Role of Tactics in Determining Objectives}

Another way of perceiving how tactics might have operated within this interaction is shown in Figure 2.

Figure 2 demonstrates how the tactics employed by both participants influence the topic - in this case, possible modification to the Student Grants scheme - and how this subsequently modifies the objectives for the interaction put forward by the participants.

Tactics act as a "valve" (this notion is borrowed from general systems theory) to enable the topic to evolve over a period of time. This concept of topic - which in itself is a very abstract concept - is a local one, where a chain of topics evolve with each successive utterance (McLaughlin 1984). It was by using this principle that the transcript was divided into episodes.

How objectives change throughout can best be illustrated by the following excerpts from the interaction. Referring back to Episode 1 the analyst outlines a possible objective for the interaction:

Basically we are looking at...how the database works and possibly some of the points we are thinking about improving...you know, recording of information.

At the end of the interaction, the objectives have been transformed into a possible solution: 
Analyst: So probably have a look at the total numbers of those, and see if it is feasible, possibly, to keep some sort of indication, maybe just the reference number of the approval code?

Client: Yeah.

Analyst: Or the status or something like that?

Client: Sounds exactly what we need.

\section{CONCLUSION}

Presented in this paper is a detailed examination of the evolution of a research methodology used to investigate analyst-client interaction and a rich description of what took place between an analyst and client in the case study. In addition, some initial analytic concepts derived directly from the data are offered. As such, the contribution of the paper can be judged from a number of perspectives.

First, the methodology put forward demonstrates the need to tailor the research method to the object of investigation and how the data and analytic concepts interact in an iterative fashion. The process of coding, establishing relationships, and understanding a phenomena at the micro level warrants full explanation as it is integral to a full understanding of the data. In addition, Strauss and Corbin recommend that special procedures be explained in order to enable to help readers judge the overall adequacy of the research. Wolcott claims that qualitative researchers no longer have to justify their methods, but they can and should give insights into how the data gathering was conducted and ensure that generalisations made are made with care.

Second, the emergent core categories and subcategories put forward assist generation of a theory as to how analysts and their clients tackle requirements gathering. By generating a rich description of the findings, there is the benefit of close contact with the data and gaining an insight into how the participants come to agreement regarding system solutions, what interactional tactics they use, and how they conceptualize information system elements such as actions, conditions and processes.

Finally, the analytic concepts generated in this case study, interactional tactics and conceptualization of information system, together with their associated subcategories, enable a demonstration of how analyst and client reach agreement. The interactional tactics of reframing, imagining, props, and rapport building, are used in the case study interaction to aid conceptualization of an information system. Use of these tactics during episodes of interaction to conceptualize an information system demonstrate how the two core categories are interrelated. The concepts of actions, processes and information and associated subcategories in the case study offer an insight into the conceptual schemas used by analysts and their clients with regard to information systems.

The following two sections of the paper assess the use of grounded theory methodology in this case study and consider how the findings might assist current practice in systems analysis. 


\subsection{Evaluating the Use of Grounded Theory Methodology}

When evaluating the use of grounded theory techniques in this case study, it could be asked whether this is truly a grounded theory study or a case study that borrows from these methods to structure qualitative analysis. To some extent, this evaluation depends on whether one regards slavish following of procedures as a hallmark of a grounded theory study, and indeed whether one regards these procedures as the only way to do a grounded theory study. In the light of serious disagreement (Glaser 1992) between the co-originators of grounded theory (Glaser and Strauss 1967) about published procedures (Strauss 1987; Strauss and Corbin 1990), conformity to these procedures should probably not be a paramount consideration for evaluating grounded theory studies. However, this is not to say that the procedures followed should not be open to evaluation.

Given Glaser's (1992) criticism of the publication of such procedures, and Strauss's injunction to modify procedures as appropriate, use of procedures is clearly a moot point. Glaser regards the use of the paradigm as "forcing" the data, rather than allowing core categories to emerge naturally. Certainly use of the paradigm in this case study was not forced; either the data fitted or it did not. Because of that lack of fit, other ways of considering relationships were sought, resulting in the use of Spradley's semantic relationships.

Another way of evaluating the use of grounded theory in the case study is to use Strauss and Corbin's seven criteria for judging a grounded theory study in conjunction with Glaser's (1992) response to those criteria.

The Canon of Reproducibility. Strauss and Corbin state that a researcher using the same methods ought to be able to come up with the same theoretical explanation. Glaser (1992) challenges this by saying that a substantive grounded theory continues generalising a process to continue its fit and work and relevance. While full conceptual description might require replication, it is difficult to reproduce grounded theory as it is fluid and changeable.

Clearly, in this case study, the theory is evolving, and replication at this time is difficult. In this researcher's opinion, this does not gainsay the use of technical literature to supplement or contradict analyses.

The Canon of Generalizability. Strauss and Corbin state that a grounded theory study is generalisable to specific situations only. Glaser (1992) points out that taking a process-based view rather than a unit based view should enable generalization from a substantive theory with limited scope to a process of larger scope based on its ability to fit, work and be relevant. Processes are not only durable and stable over time but can also account for change over time (Glaser 1978), and may have wider implications. One possibility for this study then is to see if the process of negotiation between analyst and client resembles the process of negotiation in other professional fields.

Criterion 1: Are concepts generated? This criterion assesses whether the concepts are grounded in the data, or at least if technical or common sense categories are applied to the data. Clearly the case study fits this criterion. 
Criterion 2: Are the concepts systematically related? This criterion asks if conceptual linkages have been made and if they are grounded in the data. The case study gives many examples from the data of linkages between concepts and so fits this criterion.

Criterion 3: Are there many conceptual linkages and are the categories well developed? Do they have conceptual density? This criterion asks if the categories and subcategories are tightly linked and whether the categories are theoretically dense in terms of their properties. Although it has not been possible to completely demonstrate theoretical saturation (Strauss 1987) in this paper due to confines of space, the open coding process and axial coding resulted in categories of dense properties with many dimensions. It could be argued that the selective application of the paradigm meant there were less linkages, but applying Spradley's domain analysis ensured that the links made were exhaustive. Therefore, the study could be viewed as fitting with this criterion in spite of the unorthodox manner in which the paradigm was used.

Criterion 4: Is much variation built into the theory? This criterion states that a feature of grounded theory is that it specifies variations in the theory, and establishes more than a few conditions, actions and consequences related to the phenomena under study. While multiple interpretations of the data are given in the findings, these have yet to be fully explored. This case study is one of a series of six on the same phenomena. The categories and codes put forward in this case study are being applied to other case studies. Further instances of conditions, actions and consequences will be found, codes further dimensionalised, and more variations discovered. The emergent theory is constructed in such a way that these variations can be easily incorporated.

Criterion 5: Are the broader conditions that affect the study built into its explanation? This criterion specifies that the analysis should not be so "microscopic" as to disregard "macroscopic" sources such as economic conditions, social movements, trends, cultural values and so forth. Glaser (1992) regards this criterion as a good example of "forcing" the data rather than allowing concepts to emerge. Clearly, incorporation of macroscopic sources is problematic in a study that focuses on the analysis of interaction.

If language is indeed the surface realization of social and contextual processes (Candlin 1985), then some of the analytic concepts from the dialogue do implicitly include some of these broader conditions. For instance, the way the systems analyst conceptualizes various elements of the information system in the case study is founded in previous experience and training and this information is contained in one of the data sources. Similarly, the client's reference to the department in Episode 5 reveals something of the culture of the department. The focus of the case study on interaction tactics and conceptualization means that these are considered first and foremost. The use of broader conditions here can be seen as a means of providing alternative explanations for the phenomena observed. This is the purpose of having multiple data sources in the case study.

Criterion 6: Has process been taken into account? This criterion asks if identifying movement and change in the form of process is considered. Given that the case 
study has a processual focus and that the findings are presented in such a manner as to reflect the passage of time, it must be assumed that this criterion has been satisfied.

Criterion 7: Do the theoretical findings seem significant and to what extent? This criterion states that a grounded theory study can fail to produce findings of any significance if the grounded theory "canons" or procedures are applied without imagination or insight. This would seem to be a further caution against following the method without fully understanding the requirements of the research. Analytic ability, theoretical sensitivity, sensitivity to the subtleties of the interaction and sufficient writing ability to convey the findings are required from the researcher. In addition, the data has to be fully drawn upon and data collection has to be sufficient. The design of the case study, with its multiple sources, should ensure that the data is fully examined from differing perspectives. Theoretical sensitivity, analytical procedures, sensitivity to subtleties of interaction and writing to convey findings are all demonstrated in this paper. The findings at this time do seem to fit within some of Glaser's (1992) criteria in being parsimonious, relevant and having a satisfactory fit with the data.

Strauss and Corbin also point out that the above criteria should be regarded as guidelines rather than fixed, and that new areas of investigation require that procedures and evaluative guidelines be modified to fit the circumstances of the research. The work presented falls into this category as procedures have been modified in accordance with the focus of the research. Given that most discourse analysis either addresses structural or processual aspects due to the sheer difficulty of analysing large amounts of dialogue, it could be said that Criterion 5 in particular is not entirely appropriate for a study of this nature. For instance, broader conditions such as social movements can be regarded as only having a marginal impact on the detailed business of how analysts and clients reach agreement. This research not only examines social processes but also how a standard professional task - requirements gathering interacts with it. How the system is conceptualized is at least as important as the social processes used.

The criticism of Criterion 5 notwithstanding, Strauss and Corbin do recommend that readers should be apprised of how exactly the study departs from the given criteria. This section performs that function, so that readers can evaluate the case study with reference to those criteria.

\subsection{How the Findings Might Assist Current Practice}

Some systems analysis texts (Kendall and Kendall 1995) provide excellent advice to a systems analyst engaged in requirements gathering with regard to setting up interviews, use of information sources, use of metaphors in interpreting organisational literature, and structuring interviews. However, detailed consideration of social processes is unfortunately given scant treatment in most traditional systems analysis textbooks. This is surprising, given the impact of social processes on project failure (Edstrom 1977; DeMarco and Lister 1987; Rothfeder 1988; Kennedy 1994). Perhaps 
this not too surprising when one considers that current teaching of systems analysis has but a short time within an undergraduate program to convey many technical concepts, which the systems analyst must possess in order to design an information system. In other words, attention is given to conceptualization of an information system rather than the interactional tactics required to elicit the information upon which the conceptualization is based. As this case study has demonstrated, these two issues are intimately intertwined. It is difficult for systems analysts to perform well if they are not competent at both. It is interesting to note that all the analysts involved in the six case studies felt communication with clients to be an important issue and one where they felt detailed examination would be helpful. This perhaps indicates that they felt more skilled at conceptualization than interactional tactics.

The findings from this case study could assist current practice in the following ways.

Use of reframes. Reframing is a powerful interactional tactic that influences conceptualization. If systems analysts were aware of reframing in general and the concepts of problem identification, forward reframes and reparcelling in particular, they would become sensitive to how the labeling of an object or an idea using certain words influences the joint perception of an information system. In a previous study, Guinan concentrated on framing rather than reframing and suggested outcome framing (suggesting goals), backtrack framing, pointers, an "a if" frame, and metaframing (looking at the issues as a whole). Some of these concepts have been coded differently in this study, and it was difficult to find instances of some of them. As this study looks at how shared meaning evolves between an analyst and a client, reframing is an important category as it represents a tactic by which meaning changes throughout the interaction.

Use of props. Systems analysts are not given much advice in systems analysis texts as to the use of props except with regard to prototyping input. Most systems analysts stumble on to the use of props such as finding whiteboarding a good way to work with a client. If the use of props was to be formally discussed, systems analysts would become aware of a range of possibilities to aid communication between themselves and the client. Consideration of props in a formal manner would also demonstrate the different ways people process information. Some clients who do not react well to data flow diagrams, for instance, might react better to other mechanisms.

Use of imagining and associated tactics. If systems analysts were to be formally trained in "stepping through" a process to the extent of using metaphors, acting out and vivid description, they would gain greater insights into the processes being discussed. Certainly this tactic worked well for the analyst and client in this case study. This was to some extent dependent on the analyst being able to enter into the client's mode of thinking. Perhaps systems analysts should also consider how best to do this. The notion of entering into another person's mode of thinking carries with it an implicit assumption that multiple views of a system are possible. The consideration of linguistic views in current data modelling research (Milton and Keen 1996) reflects the importance of multiple views as an issue in analyst-client communication. 
Rapport building and joint ownership. The role of rapport building in eliciting information, and the importance of joint ownership of solutions, was clearly illustrated in this case study, yet systems analysis texts do not pay much regard to either issue. Previous studies (Guinan 1988; Tan 1989) regarded rapport as an important variable in analyst-client interaction. In other types of interviewing (Dwyer 1992), rapport is regarded as an important element. This case study demonstrated that information processing between analyst and client speeded up after the establishing of rapport. Similarly, the tactic of joint ownership ensures that solutions are jointly owned and this is important in ensuring the success of an implemented system. Systems analysts need to be aware of the role of such tactics in interaction in gaining information and cooperation.

Use of the concepts of actions, processes and information. By consciously labeling actions, processes, information and associated conditions, the conceptualization of an information system during an interaction could be greatly strengthened. A supporting document (or prop) requiring this identification could be used throughout the interaction. Such a document would have to be very carefully designed so as not to stifle interaction. One of the remaining case studies, not described in this paper, used a supporting form to structure the discussion, but it had a unexpected effect on the interaction as the client was not conversant with the concepts therein. An alternative way of using these concepts would be for the analyst to explain to the client how they can be used to build up a joint picture of the information system.

Summary. By looking at how these emergent concepts could be applied to current practice, it becomes clear that the contribution of this case study comes from its detailed examination of interaction. The value of these concepts would come from their explicit use and teaching to systems analysts. Most systems analysts are not aware of the tactics they employ or how they impact on the shared perception of an information system. Therefore, it can be seen that the emergent core categories of interaction tactics and conceptualization, together with their associated categories, provide valuable insights that can be incorporated into current practice.

\subsection{Further Work}

A problem when analysing discourse is the interrelated nature of the structure of the text and the social relationships it represents (Candlin 1985). Therefore, when attempting to discover how participants reach shared perceptions regarding a system, one is of necessity decoding the social process that allows this to take place. Nevertheless, it is hoped that further work on the relationships between core and subcategories will allow an examination of how shared meaning is built up between participants. This probably requires a more detailed examination of temporal factors, of which the narrative of the interaction in the six episodes presented constitutes a first step. At first glance, the structure of the interaction fits the sequence advanced in an earlier paper of task definition, problem framing, interpretation, agreed definition and possible solutions, and final agreement (Urquhart 1995). 
This paper does not address the role of nonverbal signals and intonation to the development of shared understanding. Halliday (1979) points out that intonation acts as a means of saying different things and that if you change the intonation of a sentence you change the meaning. Nonverbal elements are said to comprise $75 \%$ of human communication (Dwyer 1992), yet a surprising amount of discourse analysis is done on written words as opposed to spoken words. When dealing with something as complex as human communication, it is difficult to address all elements: the size of the data analysis task probably contributes to this tendency to specialise in one direction or the other. One issue here is that nonverbal elements are said to contribute to conversation structure (McLaughlin 1984) and this may be of importance in professional interactions such as analyst-client conversations where the outcome is important and related to a specific task.

This research is no exception: the majority of the analysis has been done from transcripts of the videotaped interaction as a practical necessity. However, the researcher has periodically checked the videotape, where the meaning intended by the participant is unclear or where the code assigned seems problematic, in order to gain further information by examination of nonverbal indicators or tone of voice. In addition the review of the videotape, itself on videotape, has acted as a further cross check. This case study would benefit from a separate analysis of nonverbal signals and paralinguistic features.

To conclude, this case study provides some valuable insights into interactional tactics and how these interrelate with conceptualization of information systems. Examination of other data sources associated with the case study will further extend the emergent theory as presented here. Examination of the remaining case studies will provide alternative explanations, will confirm or challenge the theory, and will further saturate categories. The final aim is to provide a robust theory of how analysts and their clients reach shared understanding. Given the importance of requirements gathering to successful information systems, it is hoped that the emergent theory put forward here will contribute to current systems analysis practice.

\section{ACKNOWLEDGMENTS}

The author would like to thank the participants for giving their time so willingly and allowing data about their conversation to be shared in this paper. Thanks are also due to the Information Systems Group at the University of Tasmania and colleagues at the University of Melbourne for comments on earlier drafts. I am indebted to referees of IFIP 8.2 for their helpful and constructive feedback. Finally thanks are due to Chris Greaves and Frances Separovic for their numerous and helpful proof reading suggestions. 


\section{REFERENCES}

Banks, S. P.; Ge, G.; and Baker J (1991). "Intercultural Encounters and Miscommunication." In N. Coupland, H. Giles, and M. J. Wiemann (Editors), Miscommunication and Problematic Talk. Newbury Park, California: Sage Publications.

Bateson, G. (1972). Steps to an Ecology of Mind. New York: Ballintine.

Barnett, G. A.,and Kincaid, D. L. (1983). "Cultural Convergence: A Mathematical Theory." In W. Gudykunst (Editor), Intercultural Communication Theory: Current Perspectives. Beverley Hills: Sage Publications.

Barrett, R. A., and Davis, B. C. (1986). "Successful Systems Analysts Hone Their Communication Skills." Data Management, Volume 24, Number 4, April, pp. pp $18-21$.

Baronas, A. K., and Louis, M. R. (1988). "Restoring a Sense of Control During Implementation: How User Involvement Leads to System Acceptance." MIS Quarterly, Volume 12, Number 2, March, pp. 111-123.

Benbasat, I.; Dexter, A. S.; and Mantha, R. W. (1980). "Impact of Organizational Maturity on Information System Skill Needs." MIS Quarterly, Volume 4, Number 1, pp. 21-34.

Candlin C.N (1985). Preface, An Introduction to Discourse Analysis by Malcom Coulthard, Gen Series Editor C.N Candlin, 2nd Edition, London: Longman, p. ix.

Coulthard, M. (1985). An Introduction to Discourse Analysis. Second Edition. London: Longman.

Daly, J. A.; Vangelisti, A. L.; and Daughton, S. M. (1987). “The Nature and Correlates of Conversational Sensitivity." Human Communication Research, Volume 14, Number 2, Winter, pp. 167-202.

DeMarco, T., and Lister, T. (1987). Peopleware: Productive Projects and Teams. New York: Dorset House.

Dengate, G.; Cougar, J. D.; and Weber, R. (1990). "Motivational Characteristics of Australian Information Systems Personnel." The Australian Computer Journal, Volume 22, Number 3, August 1990.

Dervin, B. (1983). In S. Ward and L. Reed (Editors), Knowledge Structure and Use: Implications for Synthesis and Interpretation. Philadelphia: Temple University Press, Philadelphia, pp. 154-183.

Dey, I. (1993). Qualitative Data Analysis: A User Friendly Guide for Social Scientists. London: Routledge.

Dwyer, J. (1992). The Business Communication Handbook. Third Edition. Englewood Cliffs, New Jersey: Prentice Hall.

Eco, U. (1976). A Theory of Semiotics. Bloomington, Indiana: University of Indiana Press.

Edstrom, A. (1977). "User Influence and the Success of MIS Projects: A Contingency Approach." Human Relations, Volume 30, Number 7, pp. 580-607.

Eisenhardt, K. M. (1989). "Building Theories from Case Study Research." Academy of Management Review, Volume 14, Number 4, pp. 532-550. 
Feldman, M. (1995). Strategies for Interpreting Qualitative Data. Newbury Park, California: Sage Publications.

Ferratt, T. W, and Short, L. E. (1986). “Are Information Systems People Different: An Investigation of Motivational Differences." MIS Quarterly, Volume 10, Number 4, pp. 377-387.

Gingras, L., and McLean E. R. (1982). "Designers and Users of Information Systems: A Study of Differing Profiles." In M. Ginzberg and C. A. Ross (Editors), Proceedings of the Third International Conference on Information Systems. Ann Arbor, Michigan, December.

Ginzberg, M. J. (1981). "Early Diagnosis of MIS Implementation Failure: Promising Results and Unanswered Questions." Management Science, Volume 27, Number 4, pp. 459-475.

Glaser, B. G. (1978). Theoretical Sensitivity: Advances in the Methodology of Grounded Theory. San Francisco: Sociology Press.

Glaser, B. G. (1992). Basics of Grounded Theory Analysis: Emergence versus Forcing. San Francisco: Sociology Press.

Glaser, B. G., and Strauss A. (1967). The Discovery of Grounded Theory: Strategies for Qualitative Research. Chicago: Aldine Publishing Co.

Goffman, E. (1967). The Presentation of Self in Everyday Life. New York: Doubleday Anchor Books.

Goffman, E. (1981). Forms of Talk,. Oxford: Basil Blackwell.

Guinan, P. J. (1988). Patterns of Excellence for IS Professionals: An Analysis of Communication Behavior. Washington: ICIT Press.

Green, G. I. (1985). "Perceived Importance of Systems Analysts Job Skills, Roles and Non-Salary Incentives." MIS Quarterly, Volume 13, Number 2.

Halliday, M. (1979). Language as a Social Semiotic. London: Arnold.

Kaiser, K. M., and Bostrom, R. P. (1982). "Personality Characteristics of MIS Project Teams: An Empirical Study and Action Research Design.” MIS Quarterly, Volume 6 Number 4, December, pp. 43-60.

Kendall, K. E., and Kendall, J. E. (1995). Systems Analysis and Design. Third Edition. Englewood Cliffs, New Jersey: Prentice Hall.

Kennedy, S. (1994). "Why Users Hate Your Attitude." Informatics, February.

Manning, P. K. (1992). Organizational Communication. New York: Aldine de Greyter.

McLaughlin, M. L. (1984). Conversation: How Talk is Organized. Newbury Park, California: Sage Publications.

Milton, S., and Keen, C. (1996). "Linguistic Information Systems Modeling." Proceedings of the Seventh Australasian Conference on Information Systems, Volume 2, University of Tasmania, pp. 473-484.

Neuman, W. L. (1994). Social Research Methods, Second Edition. Old Tappan, New Jersey: Allyn and Bacon

Orlikowski, W. J. (1993). "CASE Tools as Organizational Change: Investigating Incremental and Radical Changes in Systems Development." MIS Quarterly, September, pp. 309-340. 
Palmer, R. (1969). Hermeneutics. Evanston, Illinois: Northwestern University Press.

Pettigrew, A. M. (1974). "The Influence Process Between Specialists and Executives." Personal Review, Volume 3, Number 1, Winger, pp. 24-30.

Planap, S., and Tracy, K. (1980). "Not to Change the Topic but..: A Cognitive Approach to the Study of Conversation." In D. Nimmo (Editor), Communication Yearbook 4. New Brunswick, New Jersey: Transaction.

Psathas, G. (1995). Conversion Analysis. Newbury Park, California: Sage Publications.

Rothefeder, J. (1988). "It's Late, Costly and Incompetent - but try Firing a Computer System.” Business Week, pp. 164-165

Spradley, J. (1979). The Ethnographic Interview. New York: Holt, Reinhart and Winston.

Strauss, A. (1987). Qualitative Research for Social Scientists. Cambridge, England: Cambridge University Press.

Strauss, A. and Corbin, J. (1990). Basics of Qualitative Research. Newbury Park, California: Sage Publications.

Tan, M. (1989). An Investigation into the Communication Behaviours of Systems Analysts. Unpublished Ph.D. Thesis, University of Queensland.

Urquhart, C. (1995). "Factors in Analyst-Client Communication in Requirements Definition." Proceedings of Pan Pacific Conference on Information Systems, National University of Singapore.

Watzlawick, P.; Weakland, J.; and Fisch, R. (1974). Change Principles of Problem Formation and Problem Resolution. New York: W.W. Norton.

Weimann, J. M. (1981). "Effects of Laboratory Videotaping Procedures on Selected Conversation Behaviors." Human Communications Research, Volume 7, pp. 302-311.

Wood, J. (1982). Human Communication: A Symbolic Interactionist Perspective. New York: CBS College Publishing.

Wolcott, H. (1990). Writing Up Qualitative Research. Newbury Park, California: Sage Publications.

Yin, R. (1984). Case Study Research. Newbury Park, California: Sage Publications.

\section{BIOGRAPHY}

Cathy Urquhart is a lecturer with the Department of Information Systems at the University of Melbourne. Prior to entering academe in 1990, she worked as a systems analyst in the public sector in the United Kingdom. She has taught at the University of Luton in the UK and at the University of Tasmania in Australia. She is currently completing her Ph.D. thesis in the area of analyst-client communication in requirements gathering. Her research and teaching interests encompass grounded theory, soft systems methodology, system development methodologies, management of information systems and project management. 


\section{Appendix 1 \\ Excerpt from Early Analytic Memo}

AM1 2/8/96

\section{The interaction between Clerical and Computer Systems in Case 1}

When trying to draw an integrative diagram covering system(s) and processes, I was struck by the fact that I had no relationship between the clerical and computer systems discussed, when in fact this issue is at the heart of the interaction in case 1 , and probably many other interactions between systems analysts and their clients. The relationship I came up with was one of scope - how many processes does the computer system cover, and at what point does the clerical system pick up the job and pick up output from the computer system and process it clerically. All through the interaction, one can see the analyst trying to distinguish what is carried out by the database (computer system) and what is carried out by clerical processes and other generic computer systems such as word processing and spreadsheets.

The analyst asks early on in the interaction:

29 "does the database help you with the assessment of those?"

31 "It's just to record the statistics basically?"

And the client clearly by a "process" means a computerized process:

34 "that would be good, if we could get a process"

One quick way for the analyst to start to delineate is to look at where the storage of information is located - he asks

39 "and the sort of information you put into the database, so then you've got a list of files that you keep, umm paper records"

So I would deduce that one of the implicit objectives ( I can't find anywhere where it is stated explicitly, the closest being line 7 about "improvement" and line 550 where a process of some sort is offered) is the extension of the scope of the current system. I suspect that quite often when an existing computer system is discussed, it is with this underlying agenda, as generally the client wishes to discuss some amendment that constitutes an extra process, and thereby an extension of functionality. Sometimes the amendment may be a streamlining of an existing process. So it is an interesting question as to whether all interactions about existing systems can be characterized in this way, or indeed do they only get to formal discussion if it's recognized that the client is asking for something outside the normal scope of the system (perhaps this is seen as a "big" amendment that needs a "big" discussion) 


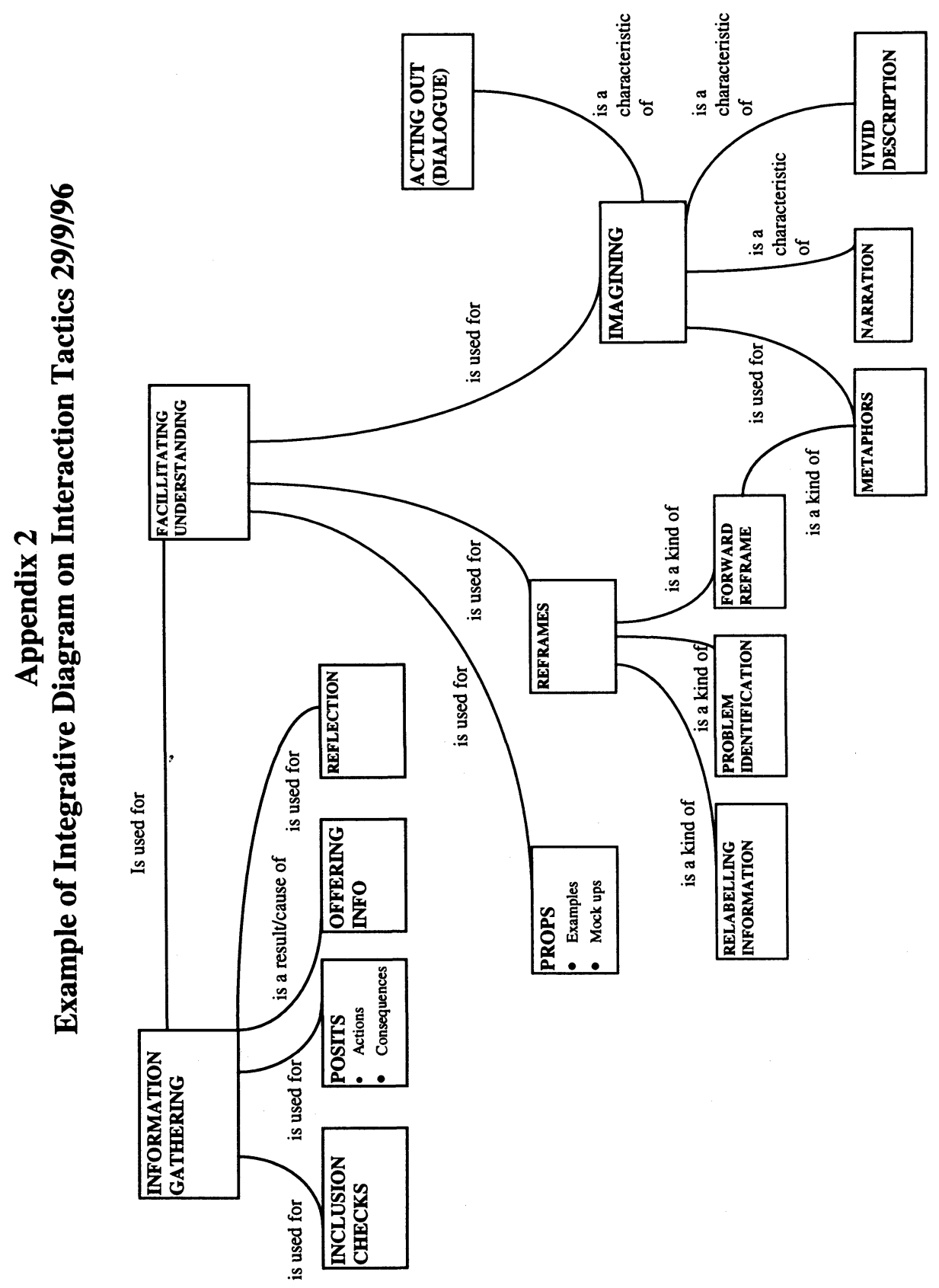

